Check for updates

Cite this: RSC Adv., 2019, 9, 33038

\title{
Toward improved wound dressings: effects of polydopamine-decorated poly(lactic-co-glycolic acid) electrospinning incorporating basic fibroblast growth factor and ponericin G1
}

\author{
Jia Zhao, (D) Fanglei Han, Wenjing Zhang, Yang Yang, Di You and Longyun Li (D)*
}

Artificial dressings composed of degradable polymer materials have a wide range of applications in skin repair. The structure and properties, in particular, the antibacterial properties, of the material surface are crucial for biological processes such as cell adhesion, proliferation, and skin regeneration. In this study, we aimed to prepare poly(lactic-co-glycolic acid) (PLGA) nanofiber scaffolds modified by polydopamine using electrospinning technology in order to produce polydopamine-modified degradable PLGA nanocomposites. The polydopamine-PLGA scaffold was endowed with excellent protein adhesion ability through the cross-linking of two biologically active factors, basic fibroblast growth factor (bFGF) and ponericin G1, significantly improving skin repair ability. The electrospun nanofiber scaffold was shown to have a structure similar to that of the natural cell matrix and created a more favorable microenvironment for cell growth. Surface modification by polydopamine dramatically improved the hydrophilicity of the nanofiber scaffold, increasing its ability to absorb active factors and its biocompatibility. The bFGF and ponericin G1 loaded onto the scaffold surface (PDA-PLGA/bFGF/ponericin G1 nanofiber scaffold) strongly promoted the antibacterial and cell proliferation-promoting properties and greatly enhanced the adhesion and proliferation of cells on the scaffold surface. The nanofiber scaffold also promoted wound healing and tissue collagen production in a rat wound healing model. Together, these findings indicate that the polydopamine-PLGA/bFGF/ponericin G1 nanofiber scaffold exhibits good biocompatibility and antibacterial properties, suggesting that it possesses potential value for skin tissue regeneration applications.

Received 3rd July 2019

Accepted 1st October 2019

DOI: $10.1039 / c 9 r a 05030 b$

rsc.li/rsc-advances growth and proliferation of seed cells and promoting self-repair of the skin. ${ }^{11}$

Electrospinning is a simple and effective method for the preparation of an ideal scaffold with natural extracellular matrix morphology ${ }^{12}$ As an electrostatic spinning material, poly(lacticco-glycolic acid) (PLGA) has the advantages of good mechanical properties, low immunogenicity, low toxicity, and an adjustable degradation rate. ${ }^{13}$ However, some deficiencies limit its use in skin tissue engineering, including its surface hydrophobicity, acidic catabolites, and lack of cell binding sites. ${ }^{14-16}$ An increasing number of modification strategies have been employed to improve the cell affinity of PLGA nanofiber scaffolds, such as physical adsorption or chemical conjugation of extracellular matrix (ECM) adhesion proteins or plasma treatment. ${ }^{17-19}$ Among them, polydopamine (PDA) is a simple, convenient, and applicable molecule for biomaterial modification. It can enhance cell adhesion and proliferation. ${ }^{19-21}$

The addition of bioactive factors can also significantly improve the biological properties of scaffold materials..$^{20}$ Generally, bioactive factors at extremely low doses can exert considerable effects. Basic fibroblast growth factor (bFGF) is 
a potent mitogen for the vasculature and can stimulate the formation of blood capillaries during wound healing. ${ }^{21-23}$ However, the poor hydrophilicity and the lack of functional groups on the polymers in the scaffold often result in a decreased growth factor loading efficiency. PDA, a mussel inspired molecule, is found in the adhesive proteins of mussels, which can improve the hydrophilic nature of a coating material and functionalize most material surfaces. Therefore, bFGF was introduced into the PDA-modified scaffold. For bFGF fixation, PDA coating is a simple and effective method eliminating the need for cumbersome surface treatments, which avoids degradation of bFGF due to its short half-life and damage by organic solvents during traditional fixation. ${ }^{24}$ It has been reported that upon immobilization by PDA coating, growth factors maintain good biological activity and sustained release capacity. ${ }^{25}$ In addition, PDA coatings can significantly promote cell adhesion and proliferation, while the concentrated metal ions of PDA can significantly promote the formation of the extracellular matrix. $^{26}$ Therefore, PDA coatings may be an effective delivery carrier for growth factors, not only reducing the dose of growth factors but also endowing the scaffold material with long-term tissue repair ability.

If a material possesses anti-infective activity while possess the capability of promote tissue regeneration, scaffolds can prevent and treat infection while promoting tissue repair, and thus have widely application value. Ponericin G1 is a natural antibacterial peptide originally extracted from ants. It has broad-spectrum antibacterial activity against microorganisms, including fungi and bacteria, and causes no damage to eukaryotic cells. ${ }^{29}$

Based on these considerations, in this study, we aimed to prepare PLGA nanofiber scaffolds by electrospinning, followed by modification with PDA (PDA-PLGA). The PDA was used to load bFGF and ponericin G1 to further enhance the tissue repair and antibacterial abilities of the electrospun nanofiber scaffold (Scheme 1). Then, the surface properties and hydrophilic properties of the nanofiber scaffold were tested, and the efficiency of the PDA coating in immobilizing bFGF and ponericin G1 was measured. This study systematically explored the effects of the PDA-PLGA/bFGF/ponericin G1 nanofiber scaffold on microbial growth as well as the proliferation, adhesion, and tissue repair-related gene expression of BALB/C 3T3 cells. We also applied the developed scaffold in a rat model of fullthickness epidermal injury to evaluate its potential impact on wound healing.

\section{Materials and methods}

\section{Reagents and instruments}

PLGA (LA : GA = 75 : 25, molecular weight 130 000, Changchun Institute of Applied Chemistry, Chinese Academy of Sciences, Changchun, Jilin Province, China), hexafluoroisopropanol (HFIP) (analytically pure, Sigma-Aldrich, St. Louis, MO, USA), dopamine hydrochloride (Sigma-Aldrich, St. Louis, MO, USA), bFGF (UB Biotech, Buffalo, NY, USA), ponericin G1 peptide (Top-peptide, Shanghai, China), Dulbecco's modified Eagle's medium (DMEM) and fetal bovine serum (Life Technologies,
Carlsbad, CA, USA), penicillin (Huabei Pharmaceutical Factory, Shijiazhuang, China), streptomycin (North China Pharmaceutical Factory, Shijiazhuang, China), trypsin (Solarbio, Beijing, China), and methylthiazolyldiphenyl-tetrazolium bromide (MTT) (Gibco, Gaithersburg, MD, USA) were acquired from various sources. Phosphate-buffered saline (PBS) was prepared in-house. Fluorescein isothiocyanate (FITC) and $4^{\prime}, 6$-bis $\left(2^{\prime}\right.$ imidazolinyl-4H,5H)-2-phenylindole (DIPI) were purchased from Sigma-Aldrich.

Equipment included a field emission scanning electron microscope (ES EM, XL30ESEM-FEG, FEL, Netherlands), fluorescence inverted microscope (Eclipse TE2000-U, Nikon, Tokyo, Japan), carbon dioxide incubator (Thermo Fisher Scientific, Waltham, MA, USA), contact angle tester (Theta Lite, KSV Instrument, Finland), and universal testing machine (Instron, Norwood, MA, USA).

\section{Preparation of PLGA nanofiber scaffold and surface modification by PDA}

First, PLGA was dissolved in $10 \mathrm{~mL}$ of HFIP solvent to make a $20 \%$ PLGA solution, which was stirred at room temperature $\left(23-26{ }^{\circ} \mathrm{C}\right.$ ) for 30 minutes. Next, the spinning solution was transferred to a syringe with a nozzle diameter of $0.45 \mathrm{~mm}$ and a volume of $2 \mathrm{~mL}$. A high-voltage device and a pusher were used to implement the electrospinning procedure, with the voltage anode connected to the syringe needle and the anode connected to the collection net (voltage: $20 \mathrm{kV}$, injection speed: $1 \mathrm{~mL} \mathrm{~h}^{-1}$, distance between the needle and the receiving device: $20 \mathrm{~cm}$ ). Finally, the prepared scaffold was dried in vacuo for 1 day to completely remove residual HFIP solvent.

For PDA-mediated surface modification of the PLGA nanofiber scaffold, dopamine hydrochloride was added to $10 \mathrm{mM}$ Tris- $\mathrm{HCl}$ solution $(\mathrm{pH}=8.0)$ to prepare a $2 \mathrm{mg} \mathrm{mL}^{-1}$ dopamine solution. Dried PLGA nanofiber samples were completely immersed in the dopamine solution and continuously shaken at room temperature for 3 hours. After successful modification by PDA, the scaffold sample was rinsed five times with deionized water to completely remove free dopamine and then lyophilized and dried in a vacuum oven until use.

\section{Characterization of scaffold materials}

The prepared PLGA and PDA-PLGA nanofiber scaffolds were sprayed with gold, and the pores and internal morphology of the scaffolds were observed by scanning electron microscopy. The surface elemental composition of the scaffolds was analyzed by energy dispersive X-ray spectroscopy (EDX). The surface hydrophilicity of each scaffold was analyzed by a contact angle tester. Static air-water contact angle measurements of the scaffold materials were obtained using the sessile drop method on a contact angle system (VCA 2000, AST). At least three droplets were dropped onto the same membrane and their contact angles were analyzed using software provided by the manufacturer. The mechanical properties of the matrices were tested by a universal mechanical testing machine (Instron 1121, UK), using nanofiber scaffolds with a width of $10 \mathrm{~mm}$ and initial length $30 \mathrm{~mm}$. Each group has three parallel samples. 


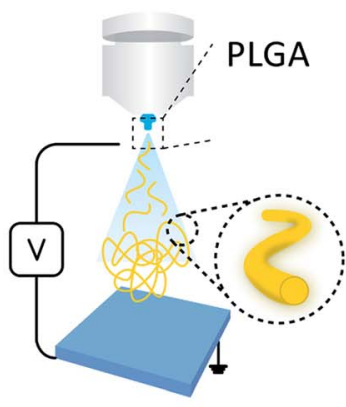

Preparation of PLGA nanofiber scaffolds

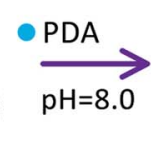

$$
\text { Su }
$$

Surface modification by PDA
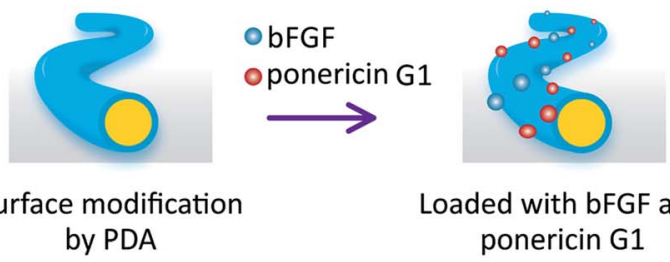

Loaded with bFGF and ponericin $\mathrm{G} 1$

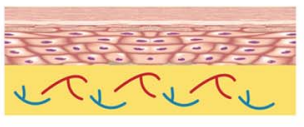

Wound healing
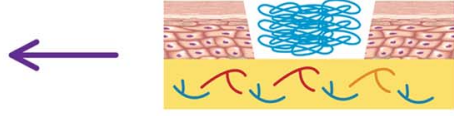

Implant the PDA-PLGA/bFGF/ ponericin $\mathrm{G} 1$ scaffolds into wound skin

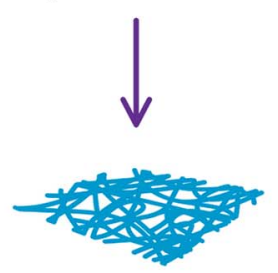

Fibrous membrane

Scheme 1 Schematic illustration of the preparation and in vivo wound repair process of the PDA-PLGA/bFGF/ponericin G1 nanofiber scaffold.

\section{Loading of electrospun nanofiber scaffold with bFGF and ponericin $\mathbf{G 1}$}

The prepared PDA-PLGA and PLGA scaffold samples were placed in 24-well plates. Subsequently, $1 \mathrm{~mL}$ of bFGF (200 ng $\left.\mathrm{mL}^{-1}\right)$ and ponericin $\mathrm{G} 1\left(250 \mu \mathrm{g} \mathrm{mL}{ }^{-1}\right)$ was added to the culture wells containing the PLGA or PDA-PLGA scaffolds, and the scaffold samples were incubated on a shaker for 2 hours at room temperature. To remove unbound cytokines, the scaffolds loaded with bFGF and ponericin G1 were rinsed thrice with distilled water, and all rinsing solutions were collected. To determine the amount of bound bFGF, the bFGF contents of different scaffold materials were measured using an enzymelinked immunosorbent assay (ELISA) kit and the following formula:

$$
\text { Binding efficiency }(\%)=\left(W_{\mathrm{a}}-W_{\mathrm{b}} / W_{\mathrm{a}}\right) \times 100 \%
$$

where $W_{\mathrm{a}}$ and $W_{\mathrm{b}}$ represent the bFGF content in the solution before and after incubation of the scaffolds, respectively.

\section{Antibacterial testing}

Antibacterial testing was conducted using Staphylococcus aureus and Escherichia coli to verify the antibacterial property of the PDA-PLGA/ponericin G1 nanofiber scaffolds. Bacterial strains were incubated in broth medium at $150 \mathrm{rpm}$ and $37^{\circ} \mathrm{C}$ for 16 hours. Then, $20 \mathrm{~mL}$ of the sterilized nutrient agar medium was poured into a $90 \mathrm{~mm}$ culture dish; after the agar had solidified, the above-mentioned bacterial suspension $(0.2 \mathrm{~mL})$ was evenly applied to the surface of the medium. PLGA, PLGA/ponericin G1, and PDA-PLGA/ponericin G1 nanofiber scaffolds of the same area were placed on the plates covered with bacteria for 24 hours at $37{ }^{\circ} \mathrm{C}$. The zones of inhibition were observed, photographed, and analyzed. In addition, to quantitatively analyze the antibacterial efficiency of the scaffold materials, scaffolds were placed in $3 \mathrm{~mL}$ of medium containing $S$. aureus and $E$. coli $\left(4.0 \times 10^{4} \mathrm{~mL}^{-1}\right)$ and cultured for 16 hours. Then, $0.1 \mathrm{~mL}$ of bacteria was sampled from each group and cultured on a new 96-well plate, and the optical density at $600 \mathrm{~nm}$ was measured using a fully automated microplate reader.

\section{Cell adhesion and proliferation assay}

Cell proliferation on the PLGA, PDA-PLGA, PDA-PLGA/bFGF, PDA-PLGA/ponericin G1, and PDA-PLGA/bFGF/ponericin G1 scaffolds was assessed. The scaffold materials were processed into discs with a diameter of $1 \mathrm{~mm}$, treated with alcohol, sterilized by ultraviolet irradiation for 40 minutes, and placed in a 24-well plate. BALB/C 3T3 cells were cultured in DMEM and expanded before being seeded into the culture plates at a density of $2 \times 10^{4}$ cells per well and incubated at $37{ }^{\circ} \mathrm{C}, 5 \%$ $\mathrm{CO}_{2}$, and 95\% humidity for 7 days. The culture medium was changed every 2 days. Four parallel samples were assessed in each group. The cell proliferation of each group was measured by MTT assay at 1, 3, and 7 days of culture.

For cell adhesion assessment, the five types of scaffold samples were placed in 24-well culture plates, and BALB/C 3T3 cells were seeded on the film at a density of $2 \times 10^{4}$ cells per well. After 3 days of culture, the cells were rinsed with PBS thrice and then treated with $4 \%$ paraformaldehyde. Cell morphology was observed using FITC and DIPI under a fluorescence microscope.

\section{Real-time PCR detection of tissue repair-related gene expression}

BALB/C 3T3 cells were cultured on the surfaces of the five types of scaffold materials as described above. After 7 days of culture, total RNA was extracted using an RNA extraction kit and reversetranscribed into cDNA. Primers were designed based on GenBank sequences and are shown in Table 1. 
Table 1 List of genes and primer nucleotide sequences

\begin{tabular}{lll}
\hline Gene annotation & Forward primer sequence & Reverse primer sequence \\
\hline COI-1 & CGCTGGCAAGAATGGCGATC & ATGCCTCTGTCACCTTGTTCG \\
& R:GGAACTTGCTTGACTATCGATCAC & 24 \\
VEGF & CCTTGCCTTGCTGCTCTACC & AGGTTTGATCCGCATGATCTG \\
GAPDH & R:GGTCAGTCAGTGCCTTTCCTC & 21 \\
& TGAACTAACACAGAGGAGGATCAG & GCTTAGGGCATGAGCTTGAC
\end{tabular}

Three parallel samples from each scaffold were amplified by real-time PCR under the following conditions: $95{ }^{\circ} \mathrm{C}$ for 3 minutes, 1 cycle; $95{ }^{\circ} \mathrm{C}$ for 10 seconds, $58{ }^{\circ} \mathrm{C}$ (annealing) for 30 seconds, 40 cycles; $65-95{ }^{\circ} \mathrm{C}$ melting curve analysis. The data were analyzed using software (MxPro v4.10; Stratagene), and the relative content of the sample was calculated by dividing the target gene concentration by the concentration of the internal reference gene (GAPDH).

\section{Cellular immunofluorescence staining}

Cells were seeded onto the scaffold material as described above and cultured for 7 days. Cells were then fixed in $4 \%$ paraformaldehyde for 2 minutes, which was repeated three times. Each sample was then incubated in $10 \%$ bovine serum at room temperature for 30 minutes. After incubation with anti-COI-1 primary antibody (Abcam, Cambridge, MA, USA), cells were conjugated with secondary antibody. Finally, the samples were stained with 4',6-diamidino-2-phenylindole (DAPI) and observed under a fluorescence microscope.

\section{Animal experiment}

Forty adult female Sprague-Dawley rats (10-12 weeks old, weighing 200-250 g) were provided by the Animal Experimental Center of Jilin University (license no. SCXK (Ji) 20110004) and were randomly divided into five groups ( $n=8$ per group): (1) PLGA, (2) PDA-PLGA, (3) PDA-PLGA/bFGF, (4) PDA-PLGA/ ponericin G1, and (5) PDA-PLGA/bFGF/ponericin G1. All animal procedures were performed in accordance with the Guidelines for Care and Use of Laboratory Animals of ChinaJapan Union Hospital of Jilin University and approved by the Animal Ethics Committee of China-Japan Union Hospital of Jilin University. The experimental animals were managed by the same breeder and housed in a standard animal room $\left(22^{\circ} \mathrm{C}\right)$. Pellet feed was routinely provided to each group, and each animal had access to food and water ad libitum. The various nanofiber scaffolds were soaked in $75 \%$ alcohol for 24 hours and disinfected with ultraviolet light. The rats were intraperitoneally anesthetized with $2 \%$ sodium pentobarbital, and the back hair of each rat was then cut with scissors. A circular fullthickness skin wound (diameter $10 \mathrm{~mm}$ ) was made on each rat's back with ophthalmic scissors. The scaffolds were implanted into the skin defects in each rat group and fixed with a band-aid. Rats were housed in single cages, and wound dressings were replaced every 2 days. Wounds were photographed using a digital camera on days $0,5,8,10$, and 12 postoperatively and measured using image analysis software (ImageJ, National Institutes of Health, Bethesda, MD, USA). The wound healing rate was determined using the following formula:

$$
\text { Wound healing rate }=\left[\left(A_{0}-A_{t}\right) / A_{0}\right] \times 100 \%
$$

where $A_{0}$ indicates the initial area of the wound $(t=0)$, and $A_{t}$ indicates the wound area at the time of measurement.

\section{Hematoxylin-eosin (H\&E) staining}

Rats were sacrificed at 7 and 12 days after scaffold implantation. To maintain the original morphological structure of the tissues, the wound tissues extracted from the rats were fixed with $4 \%$ paraformaldehyde for 24 hours. The samples were cut into $5 \mu \mathrm{m}$ sheets using a tissue cryostat (Leica CM1950, Wetzlar, Germany). The epidermal tissue was then subjected to H\&E staining and observed under an optical microscope.

\section{Immunofluorescence staining}

Wound tissues were embedded in OCT compound (Miles Scientific product no. 4583), frozen, and cut into slices. After rinsing in PBS thrice, the slices were permeabilized with $0.5 \%$ Triton X-100 for 15 minutes, washed three times with PBS, and blocked using normal goat serum for 30 minutes. The blocking solution was removed, and anti-CD31 and anti-COL-I primary antibodies (Abcam; 1 : 500) were added at $4{ }^{\circ} \mathrm{C}$ overnight. After washing thrice with PBS for 5 minutes each, secondary antibody (1:500) was added. The slices were cultured in the dark for 30 minutes, stained with DAPI for 5 minutes, rinsed thrice with PBS for 5 minutes each, and mounted. Subcutaneous vascularization and collagen formation were observed under a fluorescence microscope.

\section{Statistical analyses}

The data were analyzed by one-way analysis of variance using Origin 8.0 software (OriginLab, Los Angeles, CA, USA). Data are expressed as the mean \pm SD. Results with a value of $P<0.05$ were considered statistically significant.

\section{Results and discussion}

\section{Surface topography and surface element composition of scaffolds}

In this study, we prepared a PDA-modified nanofiber scaffold. The surface topography of PLGA and PDA-PLGA nanofiber scaffolds was observed by SEM. The PLGA electrospun scaffold 
exhibited a randomly interwoven porous network structure that simulated the extracellular matrix. This kind of structure may facilitate the exchange of nutrients and metabolites, enhance cell-cell interactions, and promote cell adhesion and diffusion. The nanofiber surface was smooth, with an average fiber diameter of $1192.4 \pm 214.2 \mathrm{~nm}$. Modification by PDA showed no significant effect on the average diameter of nanofibers $(1218 \pm$ $284.1 \mathrm{~nm}$ ) but increased the surface roughness of PLGA nanofibers. Small amounts of particle agglomerates appeared on the electrospun surface as a result of the agglomeration of dopamine. As the dopamine reaction period was extended, the number of dopamine particles gradually increased, and the particle size also increased. ${ }^{27}$ The rough surface and particle agglomerates may be caused by non-uniform surface coating. The surface roughness of the scaffold may affect various properties of the scaffold material such as hydrophilicity and protein adsorption capacity. For example, previous studies have found that protein adsorption was controlled by the surface roughness and wettability, and showing protein adsorption was greatly enhanced on rough hydrophilic materials. ${ }^{28}$ In addition, the roughness of the material surface also has a certain effect on cell proliferation and adhesion. Gao et al. have demonstrated that $10 \%$ HA could promote the cell adhesion on the microcarriers, due to its rough surface after HA doping. ${ }^{29}$ Subsequently, EDX was used to analyze the surface elements of the scaffold materials before and after modification. The main surface elements of the PLGA scaffold were carbon and oxygen (Fig. 1). The PDA-PLGA scaffold showed a nitrogen peak on the EDX spectrum. These results indicate that the PLGA nanofiber scaffold was successfully modified by PDA and covered with a PDA coating.

\section{Surface hydrophilicity and mechanical properties of electrospun nanofiber scaffolds}

As water is the main component of organisms, the hydrophilic property of a material directly determines its histocompatibility. Poor hydrophilicity may lead to difficulties in cell adhesion and penetration into the scaffold. ${ }^{30}$ The static contact angle is commonly used to evaluate the hydrophilicity of materials. ${ }^{31}$ In this study, the hydrophilicity of PDA-modified PLGA nanofiber scaffolds was evaluated through the static contact angle test. Compared with that of the PLGA scaffold $\left(99.43 \pm 5.98^{\circ}\right)$, the contact angle of the PDA-PLGA scaffold $\left(37.89 \pm 5.98^{\circ}\right)$ was significantly decreased $(P<0.05$; Fig. 2B). Contact angle generally indicates the wettability of measured substrates. ${ }^{32}$ The reduction in contact angle values clearly indicated an increase in surface hydrophilicity. ${ }^{33}$ Thus, PDA modification greatly improved the hydrophilicity of the PLGA scaffold, eliminating one drawback of the PLGA material. This may be due to the fact that the PDA coating contains various hydrophilic functional groups, thus improving the hydrophilicity of the PLGA material to some extent. Our results resembled those data reported in other publications concerning mussel-inspired poly(dopamine) surface modification. ${ }^{34}$ The mechanical strength of a material provides necessary support for the formation of new tissues. ${ }^{35}$ Therefore, good mechanical properties are essential for an ideal tissue scaffold. The tensile strength of the pure PLGA scaffold was $5.77 \pm 1.63 \mathrm{MPa}$, and this value was only slightly changed to $5.3 \pm 2.58 \mathrm{MPa}$ after PDA modification $(P>0.05$; Fig. $2 \mathrm{~A})$. This result demonstrates that surface modification by PDA did not have any negative effect on the mechanical strength of the PLGA scaffold. Thus, the whole PDA surface modification procedure
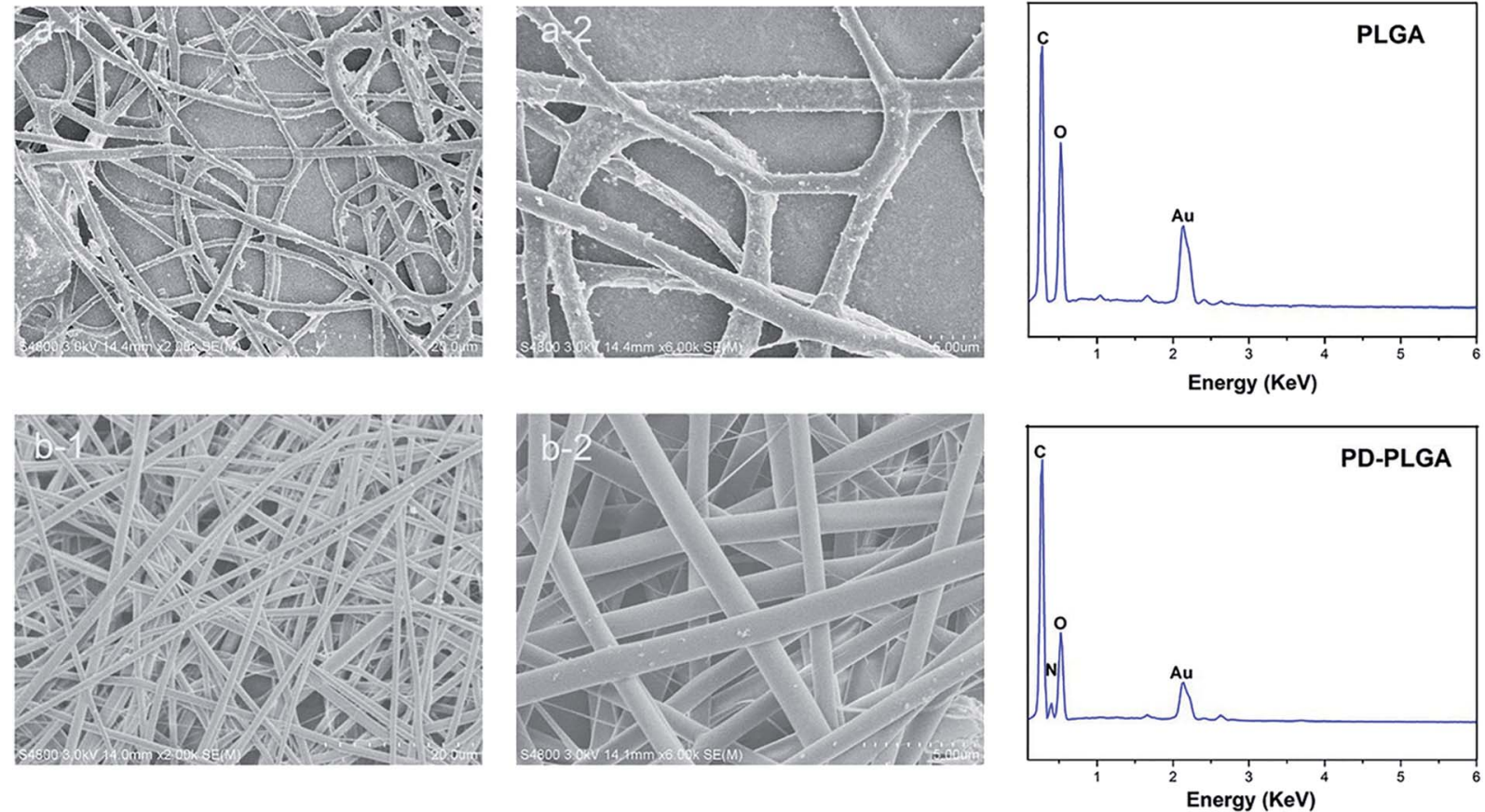

Fig. 1 Scanning electron microscope images and energy dispersive X-ray detection of pure poly (lactic-co-glycolic acid) (PLGA) (a) and polydopamine (PDA)-PLGA (b) nanofiber scaffolds. Scale bars, $20 \mu \mathrm{m}$ ( $a-1$ and b-1) and $5 \mu \mathrm{m}$ (a-2 and b-2). 
A

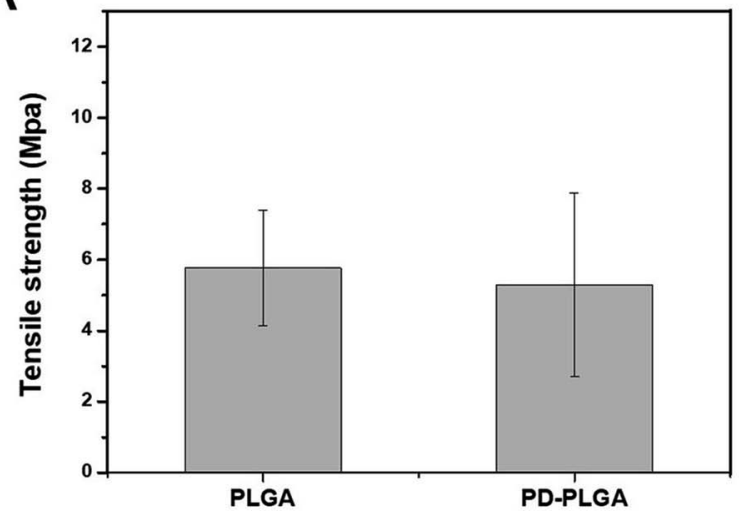

B

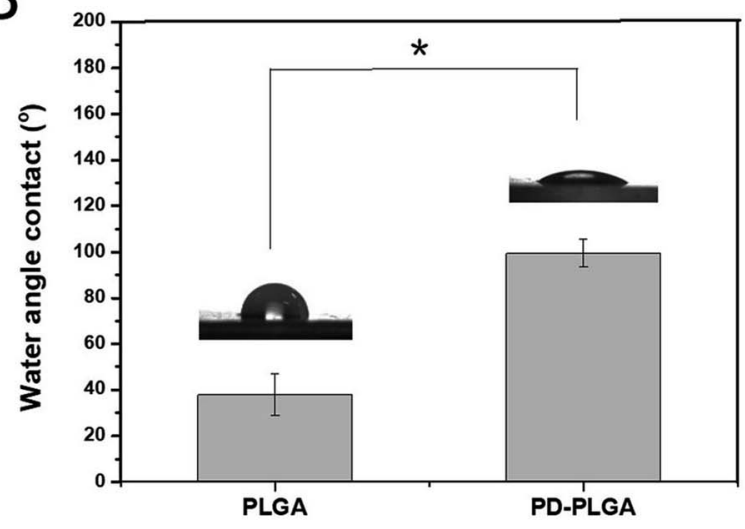

Fig. 2 Tensile strength (A) and water contact angle (B) of nanofiber scaffolds fabricated from PLGA and PDA-PLGA. $n=3, * P<0.05$.

was mild, solvent-free, non-toxic, and time-saving, which would not damage the porous structure of scaffolds.

\section{Loading efficiency of bFGF on nanofiber scaffolds}

A large number of biological phenomena that occur in the use of biomaterials are related to the adsorption of proteins on the biomaterial surface. Tissue engineering scaffolds for skin repair first must adsorb proteins in contact with the blood and then promote cell adhesion and migration. ${ }^{36}$ When the biomaterial is combined with growth factors via surface fixation, the protein adsorption efficiency of the material is critical for determining the loading efficiency of growth factors on the surface of the material. We used ELISA to detect the loading efficiency of bFGF on the scaffold surface (Fig. 3A). The loading efficiency of bFGF was $38.4 \pm 13.65 \%$ for the pure PLGA scaffold at 2 hours, and this efficiency was significantly increased to $76.45 \pm 6.43 \%$ after modification by PDA. To observe the differences between scaffolds in bFGF adsorption, FITC-labeled bFGF adsorbed on the different scaffold surfaces was observed under fluorescence microscope (Fig. 3B). Only a small number of fluorescent bright spots appeared on the surface of the PLGA nanofiber scaffold, while after PDA modification, the amount of bFGF adsorbed on the scaffold surface increased, as demonstrated by a significant increase in fluorescence and a blocky protein appearance in some areas. These results were consistent with the ELISA findings. Together, they indicate that PDA modification of electrospun nanofiber scaffolds effectively improves the adsorption efficiency of bFGF. This may be due to a Michael addition chemical reaction between an imino functional group in the dopamine and an amino group or a thiol group in the bFGF protein. ${ }^{37}$ Therefore, PDA coating is an efficient and simple method for immobilizing growth factors.

\section{Antibacterial properties of nanofiber scaffolds}

Anti-infection treatment is important for ensuring the healing of an epidermal wound. Traditional anti-infection treatments involving high doses of antibiotics delivered via systemic administration can cause unnecessary side effects. In contrast, a polymeric scaffold carrying active antibacterial molecules can reduce the use of antibiotics to a certain extent and control the release of antibiotic drugs to the wound surface at a specific stage and site. In this study, ponericin G1 absorbed on the PDA coating improved the antibacterial properties of the PDA-PLGA scaffold carrying bFGF, promoting tissue repair. We observed the antibacterial effects of scaffolds carrying ponericin G1 against $S$. aureus and E. coli (Fig. 4). Pure PLGA and PDA-PLGA nanofiber scaffolds had no bacteriostatic action, but the addition of ponericin G1 resulted in scaffolds that exhibit antibacterial activity. After 16 hours of culture on nutrient agar, nanofiber scaffolds loaded with ponericin G1 significantly inhibited E. coli and $S$. aureus growth, indicating that ponericin G1 significantly improves the antibacterial activity of the scaffold materials. Some studies have modified polymer scaffolds with ponericin G1 and found that it can endow scaffolds with good antibacterial activity. ${ }^{38}$ However, the PDA-PLGA/ponericin G1 scaffold had a stronger antibacterial effect than the PLGA/ ponericin G1 scaffold, and the zone of inhibition was greater for the PDA-PLGA/ponericin G1 scaffold than for the other scaffolds. In addition, we analyzed the antibacterial activity of the various scaffolds after 24 hours of bacterial culture and found lower optical density values in the bacterial culture medium co-cultured with the PDA-PLGA/ponericin G1 nanofiber scaffold compared to those of the other scaffolds. These findings indicate that the PDA-PLGA/ponericin G1 nanofiber scaffold exhibits a better antibacterial effect than the other scaffolds. We speculate that the PDA-PLGA scaffold has a higher immobilization efficiency of ponericin G1 than the pure PLGA because of the high protein affinity of the PDA coating. We also conclude that the ponericin G1 immobilized on the scaffold surface can maintain its biological activity for a longer period of time, ensuring that the three-dimensional scaffold has longlasting antibacterial activity.

\section{Cell proliferation and adhesion}

BALB/C 3T3 cells were implanted onto electrospun nanofiber scaffolds to systematically study the effects of PDA-PLGA/bFGF/ ponericin G1 scaffolds on cell adhesion and proliferation. Growth of the cells on the scaffold surfaces was detected using 
A

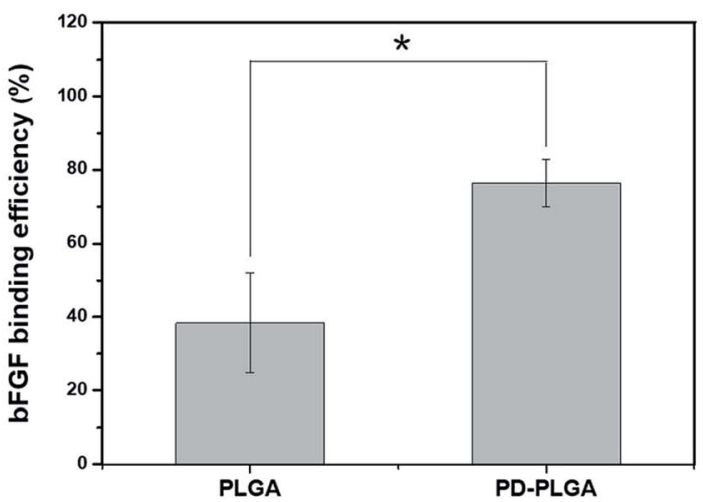

B
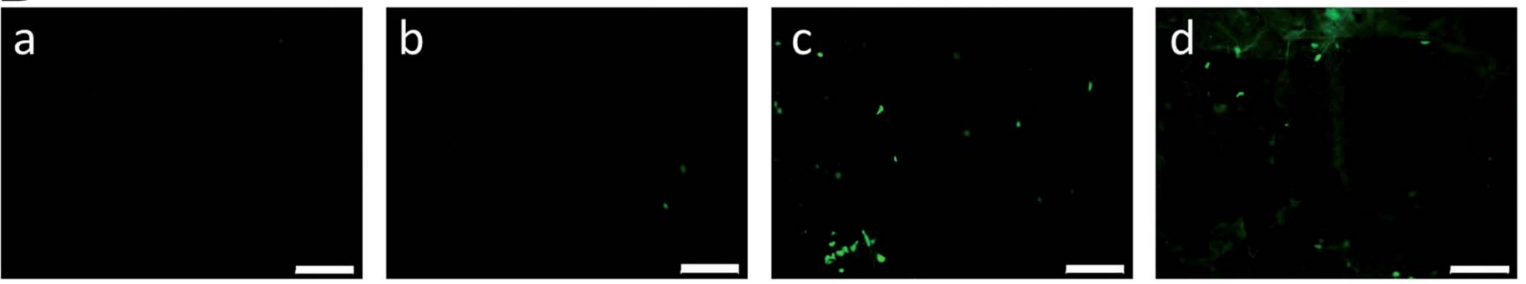

Fig. 3 Binding of basic fibroblast growth factor (bFGF) to PLGA and PDA-PLGA nanofiber scaffolds. (A) Binding efficiency of bFGF to nanofiber scaffolds. $* P<0.05$; error bars represent standard deviation for $n=3$. (B) Immunofluorescence staining of bFGF on nanofiber scaffolds. PLGA (a), PDA-PLGA (b), PLGA immersed in bFGF (c), and PDA-PLGA immersed in bFGF (d). Scale bars $=50 \mu \mathrm{m}$.

MTT assay and immunofluorescence staining at various observational time points. The proliferation of BALB/C 3T3 cells gradually increased over time, with significantly more cells in the PDA-PLGA group than in the PLGA group at 3 and 7 days of culture $(P<0.05$, Fig. $5 \mathrm{~A})$. This may be due to the improved hydrophilic properties of the modified material and the strong adhesive ability of PDA. Several previous studies have shown that PDA coating provides abundant amino and hydroxyl groups, effectively enhancing cell adhesion, proliferation, and growth. ${ }^{37,39}$ Loading of the PDA-PLGA scaffold with bFGF also significantly increased the proliferation of BALB/C 3T3 cells $(P<$ 0.05), indicating that bFGF on the surface of the scaffold has a strong ability to promote cell proliferation. As a mitotic factor, bFGF can effectively promote the growth of adult and embryonic tissues and inhibit apoptosis. Many studies have demonstrated that it can enhance the growth and proliferation of cells and promote tissue healing. ${ }^{39}$ In contrast, ponericin G1 had no influence on cell proliferation on the scaffold, indicating that ponericin G1 exerts an antibacterial effect but does not influence the viability of BALB/C 3 T3 cells.

We also observed the growth of BALB/C 3T3 cells on the different scaffolds and detected differences in cell growth (Fig. 5B). The nuclear structures of BALB/C 3T3 cells were clearly observed using fluorescence staining. Cells on the PDA-PLGA scaffold grew rapidly, and the largest number of nuclei was observed after the PDA-PLGA scaffold was loaded with bFGF. After inoculation for 3 days, plenty of adherent cells were found on the surface of each scaffold. In addition, the area of adherent cytoskeleton increased significantly, and the cells showed colony growth. The cells were interconnected more firmly and the cytoskeletal area of adherent cells was larger in the PDAPLGA group than in the PLGA group. Many previous studies have shown that various cells were able to adhere to the PDA modified surface of the various materials, grow and proliferate well. ${ }^{29,34}$ The cytoskeletal structure of the PDA-PLGA/bFGF group had a larger expanded area and an improved morphology. Upon loading of ponericin G1, there was no significant change in the number of nuclei or the cytoskeletal area of adherent cells. These findings also validate the results of the cell proliferation experiments. Together, the results of the present study indicate that the PDA-PLGA/bFGF/ponericin G1 electrospun nanofiber scaffold promotes cell proliferation and adhesion to a large extent while maintaining strong antibacterial properties.

\section{Expression of tissue repair-related genes and proteins}

The process of skin tissue repair is often accompanied by the up- or downregulation of certain genes, which can be used to evaluate the extent of tissue healing during the tissue repair period. For example, the mRNA expression levels of vascular endothelial growth factor and type I collagen (COL-I) are closely related to intercellular protein synthesis, angiogenesis, and subcutaneous collagen deposition. ${ }^{40-42}$ In this study, BALB/C 3T3 cells were cultured with various nanospinning media for 7 days, and real-time PCR was then used to detect the mRNA expression of vascular endothelial growth factor and COL-I. The expression of these mRNAs was higher in the PDA-PLGA group than in the PLGA group after 7 days of BALB/C 3T3 cell culture. Specifically, the PDA coating significantly promoted the mRNA expression of COL-I $(P<0.05$, Fig. 6A). We speculate that surface 
A
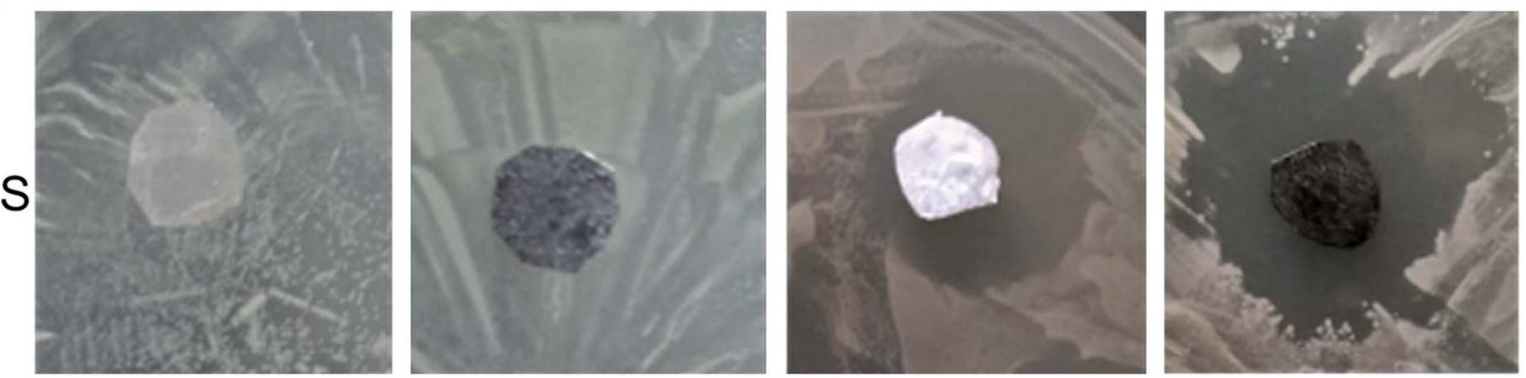

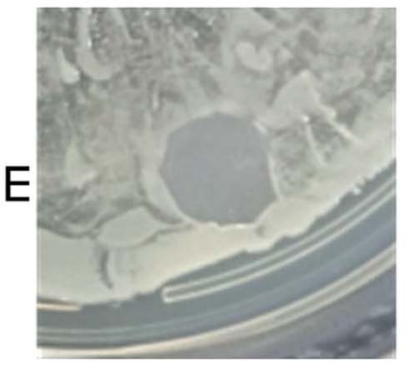

a

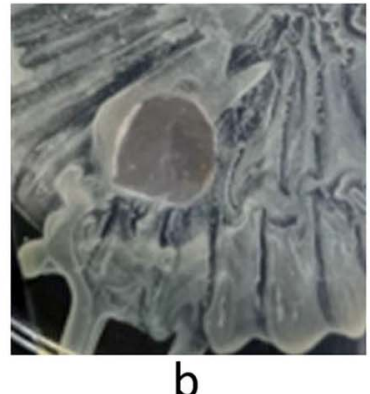

b

B

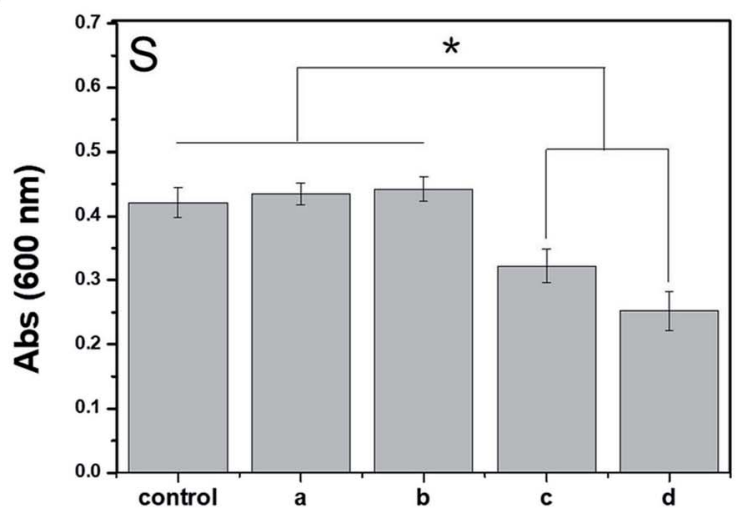

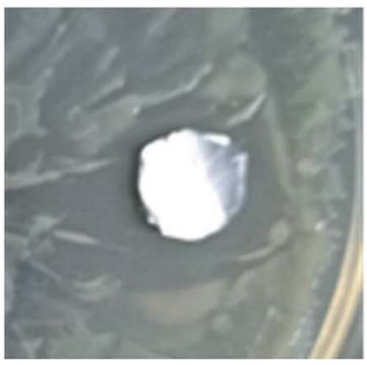

C

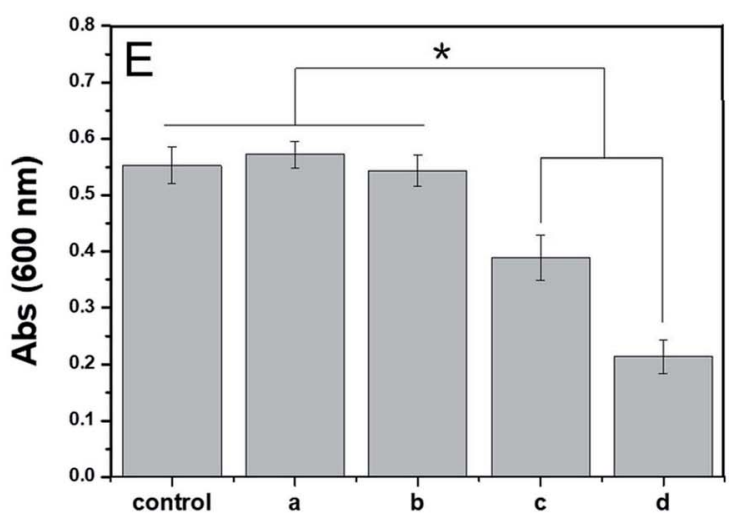

Fig. 4 Antibacterial activity of nanofiber scaffolds. (A) Zones of inhibition of nanofiber scaffolds ((a) PLGA, (b) PDA-PLGA, (c) PLGA/ponericin G1, (d) PDA-PLGA/ponericin G1) against E. coli (E) and S. aureus (S) after 16 hours of culture at $37^{\circ} \mathrm{C}$. (B) Relative antibacterial efficiency of nanofiber scaffolds against $E$. coli and $S$. aureus. ${ }^{*} P<0.05$, error bars represent standard deviation for $n=3$.

modification by PDA enhances the interaction and signal transmission between the scaffold material and cells and increases the expression of tissue repair-related genes within a certain period of time. The PDA-PLGA/bFGF electrospun nanofiber scaffold further significantly increased the expression of vascular endothelial growth factor and COL-I as compared with the PDA-PLGA scaffold ( $P<0.05$, Fig. 6A). bFGF has been confirmed to be a potent mitogen and chemotactic agent that strongly promotes the synthesis and secretion of collagen fibers and other cytoplasmic matrix components, as well as exerting a vital effect on the proliferation and vascularization of granulation tissue. ${ }^{43}$ In this study, we have also found that bFGFloaded dopamine greatly enhances the expression of genes involved in tissue repair. In contrast, the expression levels of vascular endothelial growth factor and COL-I were not significantly altered when the PDA-PLGA scaffold was loaded with ponericin G1, indicating that while ponericin G1 exhibits strong antibacterial activity, it has no significant effect on epidermal repair-related gene expression. Immunofluorescence staining was used to detect BALB/C 3T3 cells cultured on different scaffold surfaces. The protein fluorescence in the PDA-PLGA/ bFGF/ponericin G1 group was stronger than that of other groups, indicating that COL-I expression was significantly increased after bFGF was immobilized on the PDA-PLGA scaffold (Fig. 6B). Furthermore, the fluorescence intensity of PDAPLGA/bFGF/ponericin G1 was $14.03 \pm 0.73 \%$, which was significantly higher than those of PLGA, PDA-PLGA, PDA-PLGA/ bFGF and PDA-PLGA/ponericin G1 (3.70 $\pm 0.61 \%, 9.10 \pm 1.18 \%$, $9.93 \pm 1.32 \%$, and $14.59 \pm 1.02 \%$, respectively, Fig. 6C). Protein fluorescence further increased after bFGF was immobilized on the PDA-PLGA scaffold. These results indicate that the PDAPLGA/bFGF/ponericin G1 electrospun nanofiber scaffolds we 


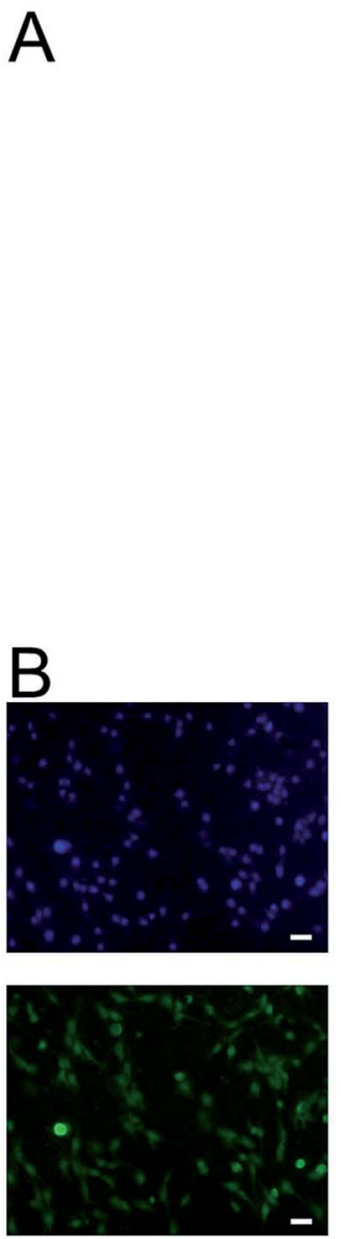

a
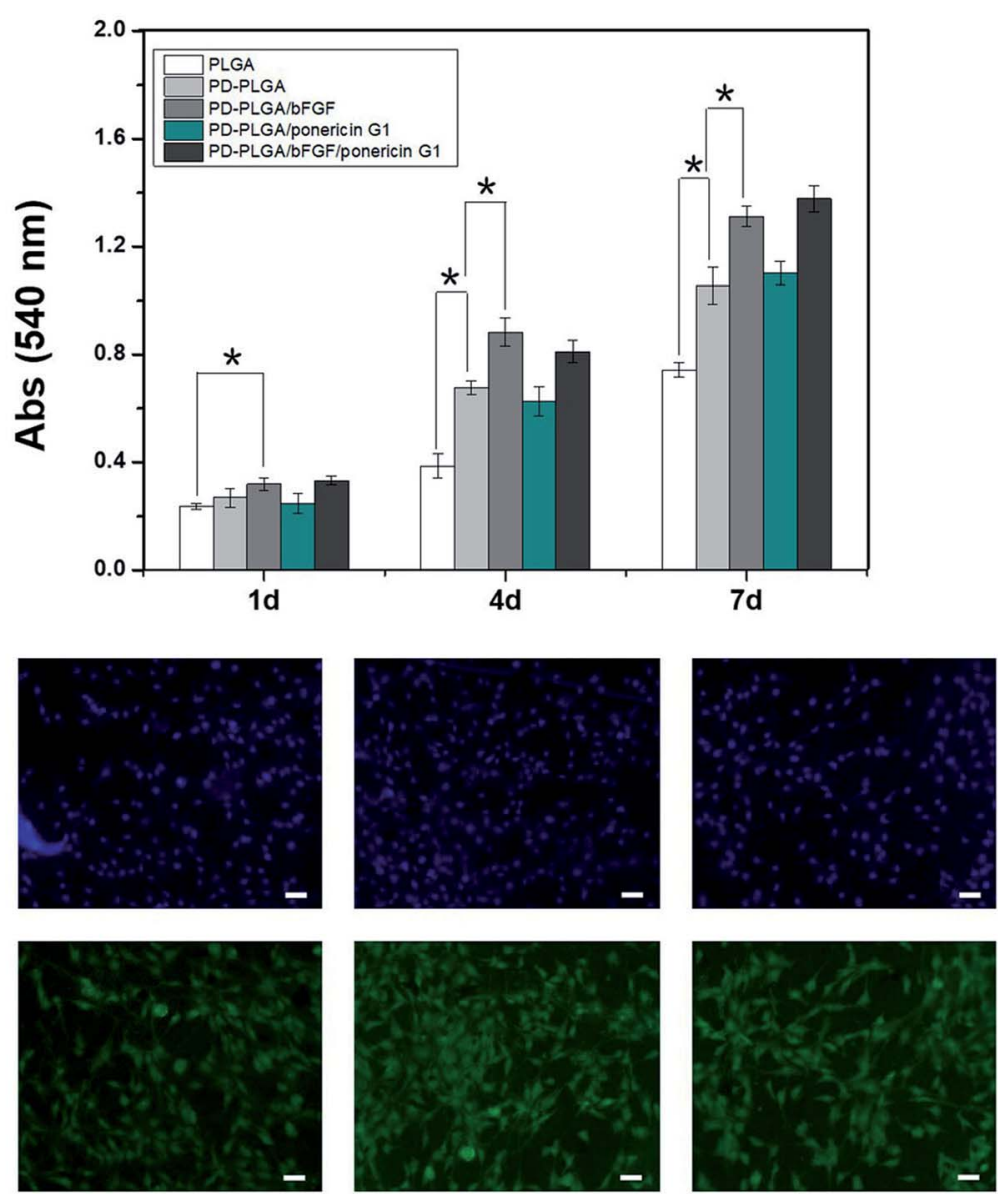

b

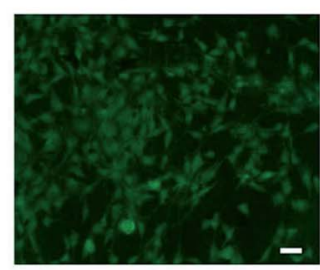

C

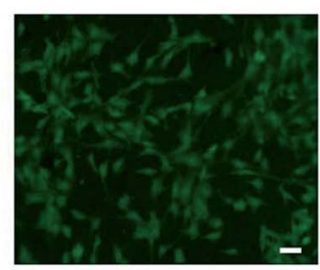

d
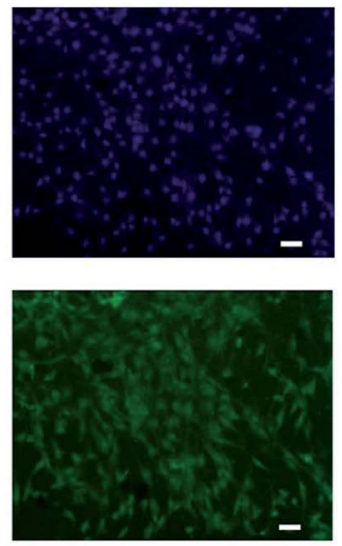

e

Fig. 5 Growth-promoting effects of nanofiber scaffolds. (A) Proliferation of BALB/C 3T3 cells in different nanofiber scaffolds as determined by methylthiazolyldiphenyl-tetrazolium bromide (MTT) assay. ${ }^{*} P<0.05, n=4$. (B) Fluorescent staining of BALB/C $3 T 3$ cells cultured on different nanofiber scaffolds ((a) PLGA, (b) PDA-PLGA, (c) PDA-PLGA/bFGF, (d) PDA-PLGA/ponericin G1, (e) PDA-PLGA/bFGF/ponericin G1) for 3 days. Scale bars, $200 \mu \mathrm{m}$.

developed can effectively promote the expression of tissue repair-related genes and proteins.

\section{Evaluation of rat epidermal injury repair}

Based on the good biological properties of the PDA-PLGA/bFGF/ ponericin G1 scaffold, we further verified its safety and effectiveness as a wound dressing in an animal experiment. Animal models of full-thickness skin lesions are commonly used to evaluate wound healing after treatment with different types of dressings. Therefore, in this study, a circular skin wound of $1 \mathrm{~cm}$ in diameter was created on the back of each rat, and wound repair was observed at 5, 8, 10, and 12 days after treatment with the different scaffolds (Fig. 7). On the 5th day postoperatively, there were no obvious hematoceles or effusion on the wound surface and no local skin redness or swelling. The rats showed no signs of obvious acute rejection and maintained normal skin temperatures. These results indicate that the electrospun nanofiber scaffolds had good tissue compatibility. The PLGA group exhibited worse wound healing and a larger wound area than the other groups. In the PDA-PLGA group, the wound healed well, and the wound area was significantly reduced. The two groups of scaffolds loaded with bFGF showed the fastest healing rate, with the average healed area exceeding $90 \%$ of the total area on the 12th day postoperatively. The increase in the healing rate was mainly due to the local sustained release of bFGF immobilized on the scaffold. As mentioned above, bFGF effectively promotes the healing of epidermal tissue owing to its ability to promote mesenchymal cell migration, proliferation, and neovascularization. Furthermore, the addition of ponericin G1 to the scaffolds significantly improved the wound healing rate, with the rate exceeding those of the PLGA and PDA-PLGA groups. Epidermal wound infections can delay wound healing to a certain extent, and microorganisms attached to the wound can gradually invade surrounding tissues, resulting in increased exudation, damage to soft tissues, and formation of erythema with pain and cellulitis; these eventually lead to delayed wound healing. ${ }^{42} \mathrm{We}$ speculate that the antibacterial activity of ponericin G1 prevents 
the occurrence of infection, thereby eliminating injury-related factors and necrotic tissue and accelerating tissue healing.

\section{Histological analysis of skin repair}

Results of H\&E staining showed that at 12 days postoperative, the wound size remained large in the PLGA and PDA-PLGA groups, with a clear boundary between the wound tissue and the surrounding tissue. These wounds were covered with a small amount of new epidermal tissues, and some scars appeared on the wound surface (Fig. 8). Moreover, inflammatory cell infiltration was more obvious in the PLGA and PDAPLGA groups than in other groups. After treatment with the

A
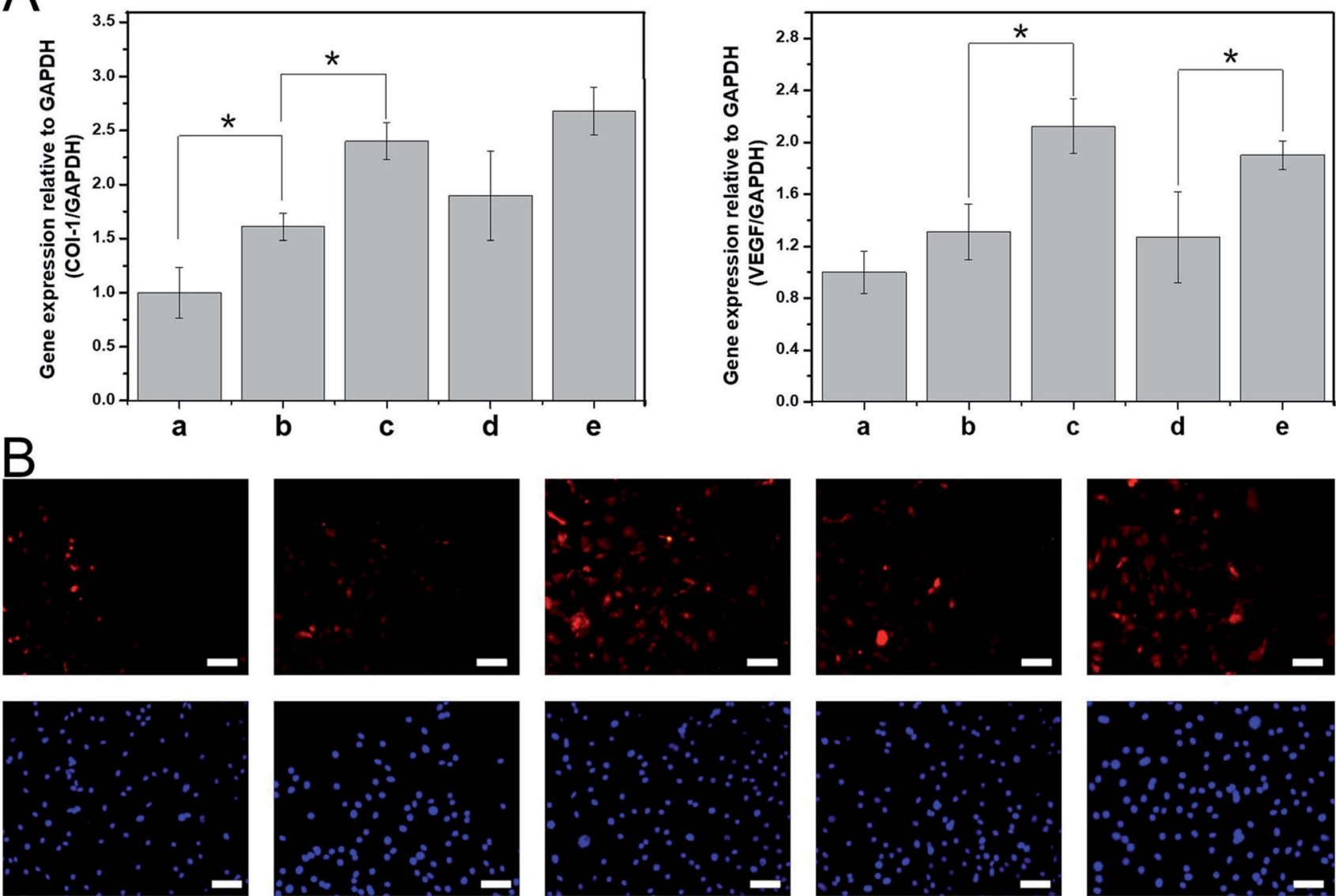

a

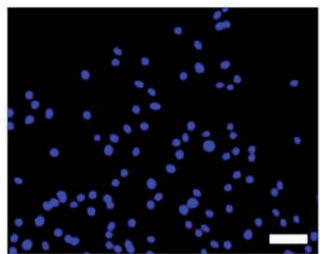

b

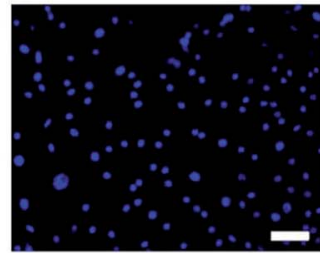

C

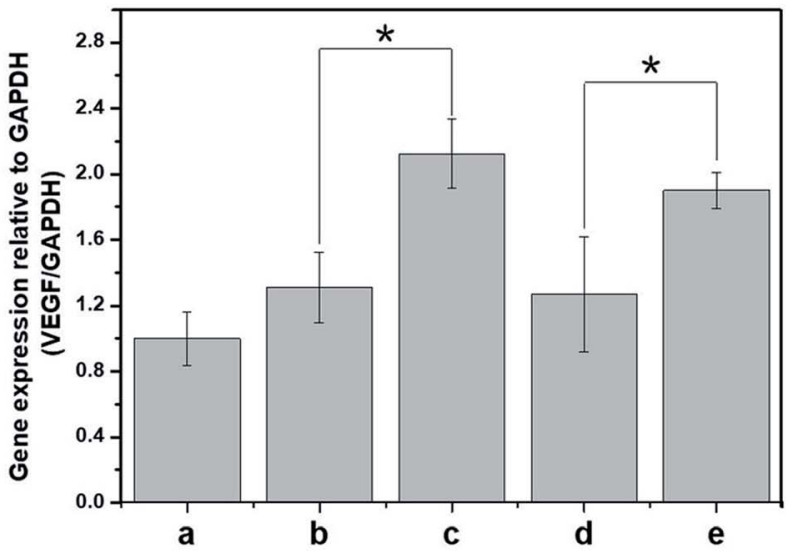

C

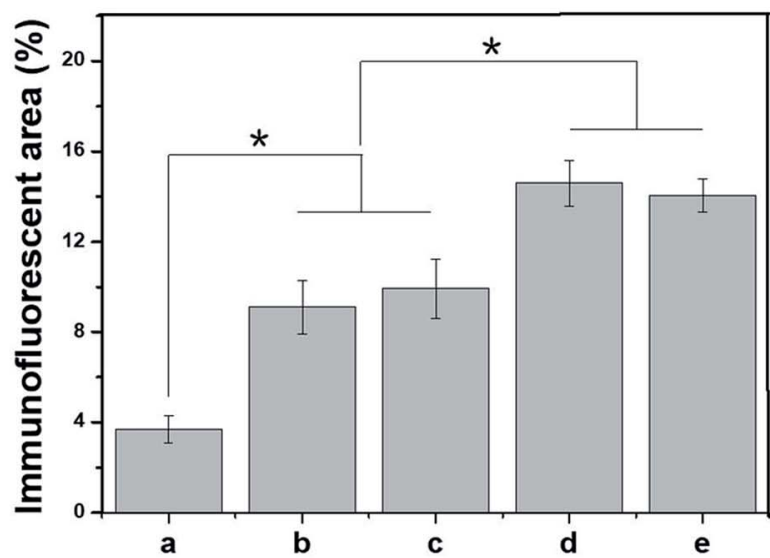

Fig. 6 Effect of nanofiber scaffolds on expression of tissue repair-related genes. (A) Real-time qPCR analysis of tissue repair-related genes VEGF and COL-I after cells were cultured for 7 days on different nanofiber scaffolds. (B) Immunofluorescent images of COL-I on different nanofiber scaffolds after 7 days. (C) Semi-quantitative analysis of immunofluorescence assay of COL-I on different nanofiber scaffolds after 7 days. (a) PLGA, (b) PDA-PLGA, (c) PDA-PLGA/bFGF, (d) PDA-PLGA/ponericin G1, (e) PDA-PLGA/bFGF/ponericin G1. Scale bars, $200 \mu$ m. 
PDA-PLGA scaffold loaded with bFGF and ponericin G1, wounds were basically healed, the stratified epithelium was well repaired, there was a high density of new vessels formed in the wound site, and fewer inflammatory cells had infiltrated as compared with results in the PLGA and PDA-PLGA groups. Since collagen is the main component in normal skin tissue, the collagen content of epidermal tissue can reflect the degree of skin healing to a certain extent. The results of the immunofluorescent staining of COL-I verified the findings of the H\&E staining (Fig. 8). In the PLGA group, the wound seemed to be in

\section{A}
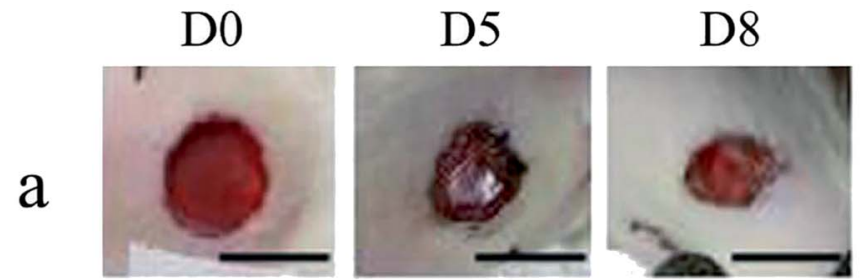

D10

D12
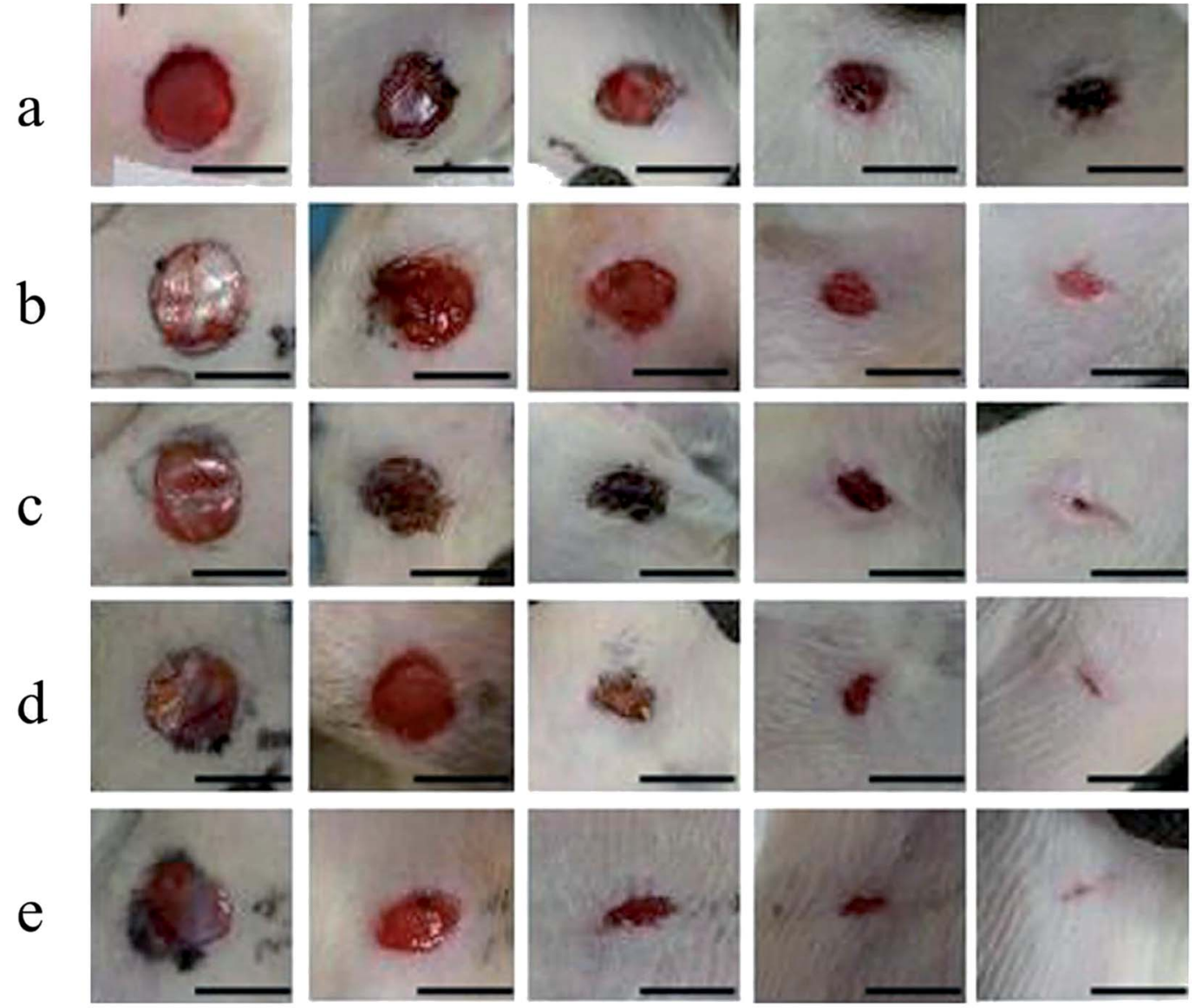

B

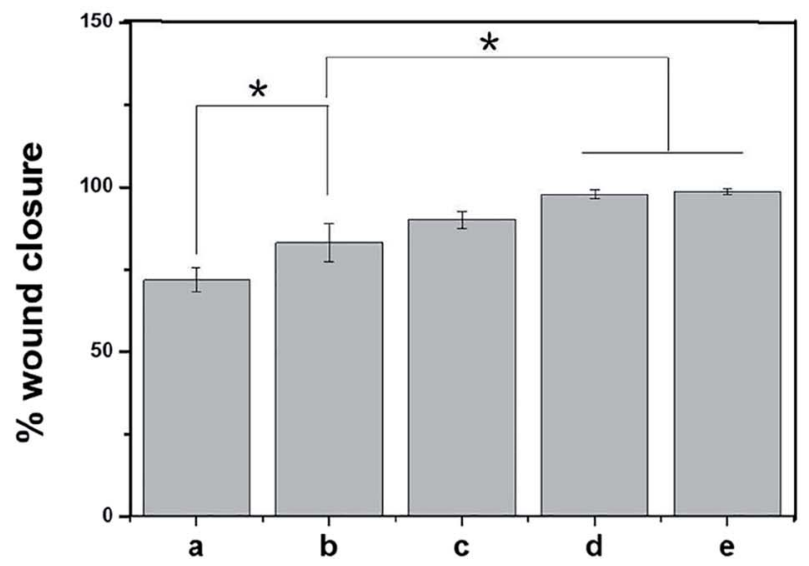

Fig. 7 Effects of nanofiber scaffolds on wound healing in vivo. (A) Gross appearance of wounds on days 0, 5, 8, 10, and 12, and (B) percentage of wound closure on day 12 for different scaffold groups. (a) PLGA, (b) PDA-PLGA, (c) PDA-PLGA/ponericin G1, (d) PDA-PLGA/bFGF, (e) PDA-PLGA/ bFGF/ponericin G1. $n=4, * P<0.05$. Scale bars, $1 \mathrm{~cm}$. 

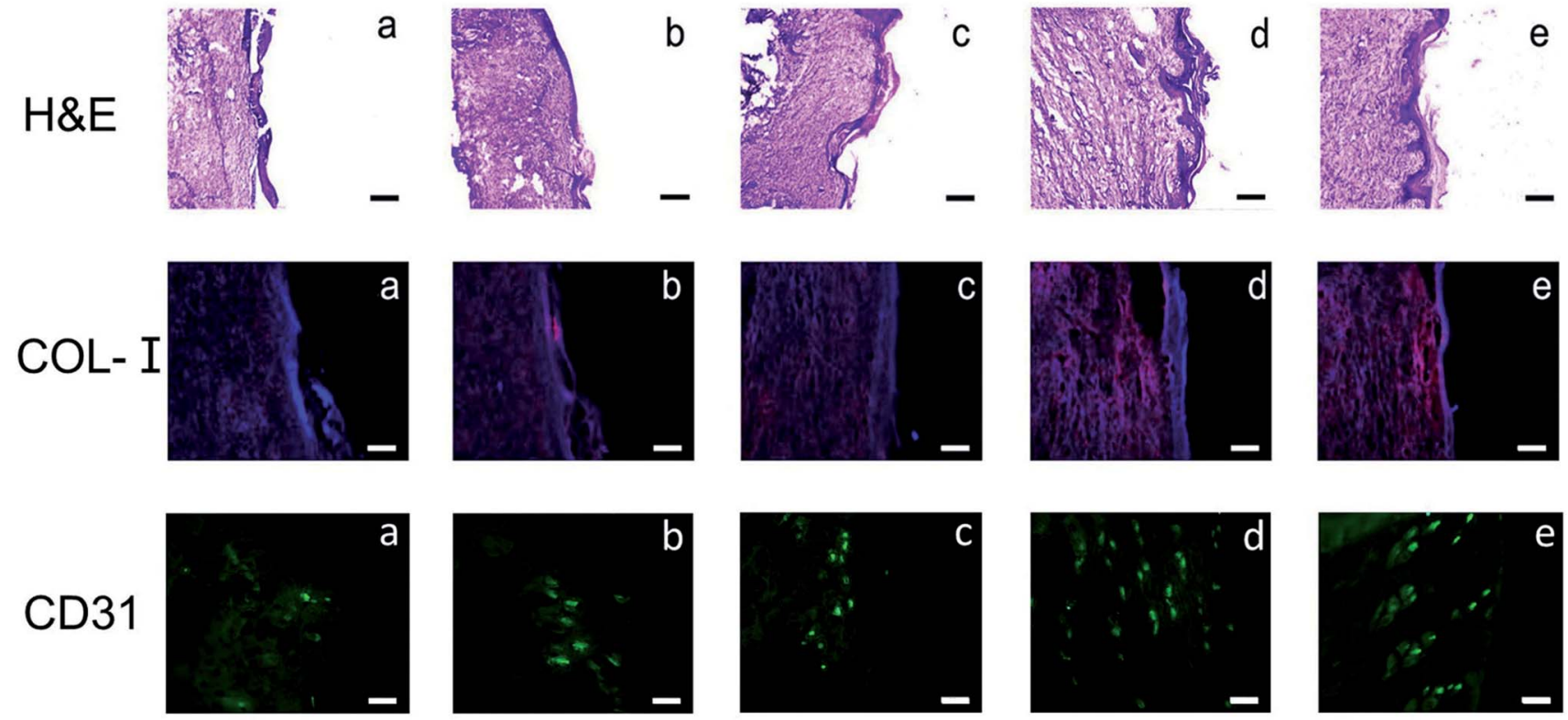

Fig. 8 Hematoxylin-eosin (H\&E) staining and immunohistochemical staining of COL-I on day 7 and of CD31 on day 12 after treatment with nanofiber scaffolds. (a) PLGA, (b) PDA-PLGA, (c) PDA-PLGA/ponericin G1, (d) PDA-PLGA/bFGF, (e) PDA-PLGA/bFGF/ponericin G1. Scale bars, 500 $\mu \mathrm{m}$ (H\&E and COL-I) and $200 \mu \mathrm{m}(\mathrm{CD} 31)$.

a proliferative phase, and therefore, the expression of COL-I was weak. In fact, type III collagen (COL-III) is the main component of granulation tissue during the proliferation of cells in wounds, and as tissue repair progresses, it is gradually replaced by COLI. ${ }^{44}$ Increasing deposition of COL-I was observed after treatment with the PDA-PLGA/ponericin G1 scaffold, indicating that PDA modification and ponericin G1 accelerated the epidermal repair in rats to some extent. The highest level of COL-I deposition was found in the PDA-PLGA/bFGF group, indicating that the PDAPLGA/bFGF electrospun nanofiber scaffold has the ability to promote wound repair.

Neovascularization is a key step in the process of epidermal repair. ${ }^{45}$ In the early repair and proliferation of skin wounds, the number of newly formed blood vessels in the injured site is temporarily increased, providing oxygen and nutrients for new granulation tissues and accelerating wound healing. ${ }^{46}$ Therefore, in this study, after the various electrospun nanofiber scaffolds were subcutaneously implanted into the backs of the rats, the effects of the electrospun nanofiber scaffolds on epidermal vascularization was assessed using the specific protein marker CD31 (platelet-endothelial cell adhesion molecule). CD31 immunofluorescence staining showed no obvious angiogenesis in the wound site at 7 days after implantation of the PLGA scaffold (Fig. 8). PDA modification and ponericin G1 improved angiogenesis slightly. Results of CD31 immunofluorescence staining clearly demonstrated that immobilization of bFGF on the scaffold promoted epidermal vascularization to the greatest extent. The strong adhesive ability of PDA enabled the bFGF immobilized on its surface to maintain its activity for an extended period and to continuously stimulate receptors on the cell surface. Therefore, more vessels formed on the surface of the PDA-PLGA/bFGF/ponericin G1 scaffold than on the other scaffolds. These findings reveal that the PDA-PLGA/bFGF/ ponericin G1 nanofiber scaffold can be used as a wound dressing with strong revascularization ability.

Electrospun scaffolds have recently drawn increasing attention in the field of tissue engineering due to their adjustable micronano structure and their ability to mimic natural extracellular matrix. Nanofiber scaffolds made from biocompatible and biodegradable materials can be used as skin dressings. These nanofiber scaffolds can selectively promote cell proliferation and tissue regeneration in combination with different cell types and bioactive factors, achieving the purpose of functionalized dressings.

Dopamine has strong adhesive abilities because of its catechol functional group and the terminal amino functional group of lysine. ${ }^{47}$ Dopamine is capable of self-polymerization in an alkaline solution, forming a highly viscous PDA layer on the surface of the material. ${ }^{48}$ Many studies have shown that PDA coating can greatly improve the hydrophilicity and biocompatibility of biomaterials. ${ }^{39}$ In this study, we prepared PLGA nanofiber scaffolds by electrospinning. The surface modification of the scaffold with PDA greatly improved the hydrophilicity of the PLGA microcarrier and promoted cell behaviors such as the adhesion and proliferation of BALB/C 3T3 cells on the surface of the PLGA scaffold. Numerous studies have found that growth factors and antibacterial drugs significantly promote epidermal tissue repair and prevent infection. ${ }^{43}$ However, a blend of growth factors and materials is often used in the preparation of polymer materials, and the addition of organic solvents during the preparation process can have impacts on the activity of growth factors. Additionally, polymer materials combined with growth factors via an adsorption approach are hydrophobic and have no surface functional groups, thus leading to a poor ability to bind to hydrophilic growth factors. ${ }^{49}$ In this study, the capacity of PLGA scaffolds to adsorb bFGF and 
ponericin G1 was greatly improved by PDA modification, and large amounts of proteins could be immobilized on the surface of the scaffold material, laying a foundation for the combination of materials and growth factors. The PDA-PLGA/bFGF/ponericin G1 scaffolds exhibited significantly improved antibacterial ability and biocompatibility and greatly promoted the proliferation and adhesion of BALB/C 3T3 cells. Moreover, the expression of tissue repair-related genes and proteins, namely vascular endothelial growth factor and type I collagen, was significantly increased. In addition, the PDA-PLGA/bFGF/ponericin G1 scaffold significantly promoted epidermal injury repair in rats, indicating that this scaffold can promote epidermal regeneration, subcutaneous collagen deposition, and subcutaneous tissue neovascularization to a considerable extent. Therefore, we speculate that PDA coatings carrying bFGF and ponericin G1 exhibit strong potential for applications in epidermal repair and artificial skin preparation. In order to develop an ideal artificial skin dressing, further investigations on the biological characteristics of PDA-PLGA/bFGF/ ponericin G1 nanofiber scaffolds are warranted in the future.

\section{Conclusions}

In summary, the PLGA nanofiber scaffold loaded with bFGF and ponericin G1 prepared by polydopamine modification developed in this study has excellent mechanical properties, hydrophilicity, and antibacterial activity. This scaffold material has appropriate morphological and surface properties that can meet the needs of skin tissue regeneration. In addition, the loading of bFGF and ponericin G1 onto the scaffolds results in good cell adhesion and proliferation properties and increases the expression of epidermal repair-related genes. A series of in vivo studies involving gross appearance, histology, and immunofluorescence showed that the PDA-PLGA/bFGF/ponericin G1 nanofiber scaffold promotes wound healing, collagen deposition, and tissue vascularization to a considerable extent. Overall, our findings indicate that the PDA-PLGA/bFGF/ponericin G1 nanofiber scaffold can promote the healing of full-thickness wounds and significantly reduce the time required to treat wounds. Therefore, it has broad application potential in the field of skin repair.

\section{Conflicts of interest}

There are no conflicts to declare.

\section{Acknowledgements}

The study was supported by the Bethune Fund of Jilin Provincial Health Department (No. 3D516M443430) and Jilin province health research talent special project.

\section{References}

1 E. Proksch, J. M. Brandner and J. M. Jensen, The skin: an indispensable barrier, Exp. Dermatol., 2008, 17, 1063-1072.
2 T. K. Hunt and H. W. Hopf, Wound healing and wound infection: what surgeons and anesthesiologists can do, Surg. Clin. North Am., 1997, 77, 587-606.

3 Y. Pilehvar-Soltanahmadi, et al. An overview on application of natural substances incorporated with electrospun nanofibrous scaffolds to development of innovative wound dressings, Mini-Rev. Med. Chem., 2018, 18, 414-427.

4 E. M. Haisma, PhD thesis, Human skin equivalents to study the prevention and treatment of wound infections, 2018.

5 S. Datta, et al. Oleoyl-chitosan-based nanofiber mats impregnated with amniotic membrane derived stem cells for accelerated full-thickness excisional wound healing, ACS Biomater. Sci. Eng., 2017, 3, 1738-1749.

6 K. Joshy, S. Snigdha and S. Thomas, Plasma Modified Polymeric Materials for Scaffolding of Bone Tissue Engineering, in Non-Thermal Plasma Technology for Polymeric Materials, Elsevier, 2019, pp. 439-458.

7 S. Petrulyte and D. Petrulis, Modern textiles and biomaterials for healthcare, in Handbook of Medical Textiles, Elsevier, 2011, pp. 1-35.

$8 \mathrm{H}$. A. Patel, et al. Wound dressings with anti-microbial and zinc-containing agents, US Pat. 7799965, U.S. Patent and Trademark Office, Washington, DC, 2010.

$9 \mathrm{H}$. Li, et al. Superabsorbent polysaccharide hydrogels based on pullulan derivate as antibacterial release wound dressing, J. Biomed. Mater. Res., Part A, 2011, 98, 31-39.

10 M. P. Prabhakaran, J. Venugopal and S. Ramakrishna, Electrospun nanostructured scaffolds for bone tissue engineering, Acta Biomater., 2009, 5, 2884-2893.

11 S. Hinderer, S. L. Layland and K. Schenke-Layland, ECM and ECM-like materials-biomaterials for applications in regenerative medicine and cancer therapy, Adv. Drug Delivery Rev., 2016, 97, 260-269.

12 Z. Rezvani, et al. A bird's eye view on the use of electrospun nanofibrous scaffolds for bone tissue engineering: current state-of-the-art, emerging directions and future trends, Nanomedicine, 2016, 12, 2181-2200.

13 D. Pandita, S. Kumar and V. Lather, Hybrid poly(lactic-coglycolic acid) nanoparticles: design and delivery prospectives, Drug discovery today, 2015, 20, 95-104.

14 D. Edith and J.-L. Six, Surface characteristics of PLA and PLGA films, Appl. Surf. Sci., 2006, 253, 2758-2764.

15 W. Di, R. S. Czarny, N. A. Fletcher, M. D. Krebs and H. A. Clark, Comparative study of poly( $\varepsilon$-caprolactone $)$ and poly(lactic-co-glycolic acid)-based nanofiber scaffolds for pH-sensing, Pharm. Res., 2016, 33, 2433-2444.

16 F. Danhier, et al. PLGA-based nanoparticles: an overview of biomedical applications, J. Controlled Release, 2012, 161, 505-522.

17 W.-B. Tsai, W.-T. Chen, H.-W. Chien, W.-H. Kuo and M.-J. Wang, Poly (dopamine) coating of scaffolds for articular cartilage tissue engineering, Acta Biomater., 2011, 7, 4187-4194.

$18 \mathrm{~L}$. Ge, et al. Polydopamine-coated paper-stack nanofibrous membranes enhancing adipose stem cells' adhesion and osteogenic differentiation, J. Mater. Chem. A, 2014, 2, 6917-6923.

19 Y. M. Shin, et al. Advanced capability of radially aligned fibrous scaffolds coated with polydopamine for guiding 
directional migration of human mesenchymal stem cells, $J$. Mater. Chem. A, 2017, 5, 8725-8737.

$20 \mathrm{~W}$. Ji, et al. Bioactive electrospun scaffolds delivering growth factors and genes for tissue engineering applications, Pharm. Res., 2011, 28, 1259-1272.

21 H. Sorg, D. J. Tilkorn, S. Hager, J. Hauser and U. Mirastschijski, Skin wound healing: an update on the current knowledge and concepts, Eur. Surg. Res., 2017, 58, 81-94.

22 R. J. Bodnar, Chemokine regulation of angiogenesis during wound healing, Adv. Wound Care, 2015, 4, 641-650.

23 N. X. Landén, D. Li and M. Ståhle, Transition from inflammation to proliferation: a critical step during wound healing, Cell. Mol. Life Sci., 2016, 73, 3861-3885.

24 D. Zhang, et al. Reinforcement of transvaginal repair using polypropylene mesh functionalized with basic fibroblast growth factor, Colloids Surf., B, 2016, 142, 10-19.

25 C.-C. Ho and S.-J. Ding, Structure, properties and applications of mussel-inspired polydopamine, J. Biomed. Nanotechnol., 2014, 10, 3063-3084.

26 S. Babitha and P. S. Korrapati, Biodegradable zeinpolydopamine polymeric scaffold impregnated with $\mathrm{TiO}_{2}$ nanoparticles for skin tissue engineering, Biomed. Mater., 2017, 12, 055008.

27 J. Jinhong, Z. Liping, Z. Lijing, Z. Baoku and X. Youyi, Surface characteristics of a self-polymerized dopamine coating deposited on hydrophobic polymer films, Langmuir, 2011, 27, 14180-14187.

$28 \mathrm{~K}$. Tsougeni, et al. Controlled protein adsorption on microfluidic channels with engineered roughness and wettability, Sens. Actuators, B, 2012, 161, 216-222.

29 T. L. Gao, et al. Biodegradable Microcarriers of Poly(Lactideco-Glycolide) and Nano-Hydroxyapatite Decorated with IGF1 via Polydopamine Coating for Enhancing Cell Proliferation and Osteogenic Differentiation, Macromol. Biosci., 2015, 15, 1070-1080.

30 N. J. Chang, Y. R. Jhung, C. K. Yao and M. L. Yeh, Hydrophilic gelatin and hyaluronic acid-treated PLGA scaffolds for cartilage tissue engineering, J. Appl. Biomater. Funct. Mater., 2013, 11, e45-52.

31 Z. Yoshimitsu, A. Nakajima, T. Watanabe and K. Hashimoto, Effects of surface structure on the hydrophobicity and sliding behavior of water droplets, Langmuir, 2002, 18, 5818-5822.

$32 \mathrm{E}$. Fortunati, et al. Combined effects of Ag nanoparticles and oxygen plasma treatment on PLGA morphological, chemical, and antibacterial properties, Biomacromolecules, 2013, 14, 626-636.

33 C. Lin, et al. Incorporation of carboxylation multiwalled carbon nanotubes into biodegradable poly(lactic-co-glycolic acid) for bone tissue engineering, Colloids Surf., B, 2011, 83, 367-375.

$34 \mathrm{X}$. M. Sun, et al. bFGF-grafted electrospun fibrous scaffolds via poly(dopamine) for skin wound healing, J. Mater. Chem. $B, 2014,2,3636-3645$.
35 A. Moroi, et al. Effect on surface character and mechanical property of unsintered hydroxyapatite/poly-l-lactic acid (uHA/PLLA) material by UV treatment, J. Biomed. Mater. Res., Part B, 2018, 106, 191-200.

36 J. I. Sheppard, W. G. Mcclung and I. A. Feuerstein, Adherent platelet morphology on adsorbed fibrinogen: effects of protein incubation time and albumin addition, J. Biomed. Mater. Res., 1994, 28, 1175-1186.

37 L. Haeshin, S. M. Dellatore, W. M. Miller and P. B. Messersmith, Mussel-inspired surface chemistry for multifunctional coatings, Science, 2007, 318, 426-430.

38 X. Y. Li, et al. Degradable Three Dimensional-Printed Polylactic Acid Scaffold with Long-Term Antibacterial Activity, ACS Sustainable Chem. Eng., 2018, 6, 2047-2054.

$39 \mathrm{Y}$. Li, et al. Electrospun biodegradable polyorganophosphazene fibrous matrix with poly(dopamine) coating for bone regeneration, J. Biomed. Mater. Res., Part A, 2015, 102, 3894-3902.

40 M. H. G. Costa, T. C. Mcdevitt, J. M. S. Cabral, C. L. D. Silva and F. C. Ferreira, Tridimensional configurations of human mesenchymal stem/stromal cells to enhance cell paracrine potential towards wound healing processes, J. Biotechnol., 2017, 262, 28-39.

$41 \mathrm{~L}$. L. Wang, et al. A fundamental study on the dynamics of multiple biomarkers in mouse excisional wounds for wound age estimation, Journal of Forensic \& Legal Medicine, 2016, 39, 138-146.

42 R. A. Ignotz, T. Endo and J. Massague, Regulation of fibronectin and type I collagen mRNA levels by transforming growth factor-beta, J. Biol. Chem., 1987, 262, 6443-6446.

43 Q. Liu, et al. Acceleration of skin regeneration in fullthickness burns by incorporation of bFGF-loaded alginate microspheres into a CMCS-PVA hydrogel, J. Tissue Eng. Regener. Med., 2017, 11, 1562.

$44 \mathrm{~J}$. Li, J. Chen and R. Kirsner, Pathophysiology of acute wound healing, Clin. Dermatol., 2007, 25, 9-18.

45 C. Qing, J. Dong and M. Tian, The Differences of Cell Biology in the Repair Process of Wound and Refractory Wound Surface, in Advanced Trauma and Surgery, Springer, 2017, pp. 323-355.

46 L. A. DiPietro, Angiogenesis and wound repair: when enough is enough, J. Leukocyte Biol., 2016, 100, 979-984.

47 A. R. Narkar, J. D. Kelley, R. Pinnaratip and B. P. Lee, Effect of ionic functional groups on the oxidation state and interfacial binding property of catechol-based adhesive, Biomacromolecules, 2017, 19, 1416-1424.

$48 \mathrm{X} . \mathrm{Xu}, \mathrm{B}$. Bai, C. Ding, H. Wang and Y. Suo, Synthesis and properties of an ecofriendly superabsorbent composite by grafting the poly(acrylic acid) onto the surface of dopamine-coated sea buckthorn branches, Ind. Eng. Chem. Res., 2015, 54, 3268-3278.

49 S. Hong, H. Xixue, Y. Fei, B. Jianzhong and W. Shenguo, Cell affinity for bFGF immobilized heparin-containing poly(lactide-co-glycolide) scaffolds, Biomaterials, 2011, 32, 3404-3412. 